\title{
The Quality of Employment and Decent Work: Definitions, Methodologies, and Ongoing Debates
}

\author{
Brendan Burchell \\ University of Cambridge
}

Kirsten Sehnbruch

University of Chile

Agnieszka Piasna

University of Cambridge

Nurjk Agloni

University of Chile

\begin{abstract}
This article explores the development of concepts related to the 'quality of employment' in the academic literature in terms of their definition, methodological progress, and ongoing policy debates. Over time, these concepts have evolved from simple studies of job satisfaction towards more comprehensive measures of job and employment quality, including the ILO's concept of 'Decent Work' launched in 1999.

This paper compares the parallel development of quality of employment measures in the European Union with the ILO's Decent Work agenda and concludes that the former has advanced much further due to more consistent efforts to generate internationally comparable data on labour markets, which permit detailed measurements and international comparisons. In contrast, Decent Work remains a very broadly defined concept, which is impossible to measure across countries.

We conclude by proposing three important differences between these two scenarios that have lead to such diverging paths: the lack of availability of internationally comparable data, the control over the research agenda by partisan social actors, and a prematurely mandated definition of Decent Work which is extremely vague and all-encompassing ${ }^{1}$
\end{abstract}

Keywords: Decent Work, Indicators, Quality of employment, Job quality, Job satisfaction

\footnotetext{
${ }^{1}$ We would like to thank three anonymous referees for their thoughtful comments that have informed and improved this article.
} 


\section{Introduction}

During the last two decades an increasing amount of public policy and academic attention has focused on different aspects of the quality of employment. Analysts have recognised that for many people just having a job may not be enough to ensure even a basic standard of living. As the dual processes of globalisation and liberalisation have generated continuous calls for labour market flexibilisation, employment conditions such as wages, job stability and career prospects have changed. Thus, the latter have become at least as important a subject of study as traditional indicators such as employment or unemployment rates.

However, the literature on the subject is very diverse and spread between academic and institutional publications. Theoretical conceptualisations of the quality of employment have been diffuse, thus limiting their political impact. Only the International Labour Organisation (ILO) has attempted a systematic definition of the quality of work through its concept "Decent Work", which was officially launched in 1999. Among those institutions influenced by the ILO's approach, the European Union (EU) and some European governments stand out (see review in Muñoz de Bustillo et al. 2011; Alli, 2009; Reinecke \& White, 2004; ILO, 2012). However, the overall impact that the concepts "quality of employment" or "Decent Work" have had on both research and public policy is extremely limited compared to the influence achieved, for example, by the human development concept and, more specifically, by the Human Development Index (HDI) over a similar period.

The purpose of this paper is to review existing debates around the quality of employment and related concepts, thus allowing for a clearer understanding of what constitutes good quality jobs and the possibility of quantifying them. Placing the quality of employment high on the policy agenda has a much better chance of success if globally relevant operationalisations derived from cross-national comparative data are developed. Academic and institutional efforts undertaken so far provide valuable lessons for achieving such a goal. This paper begins with a review of the academic and institutional literature that outlines conceptual developments over time and discusses how the relevant literature can be organised thematically. We summarise the literature that originates in the "quality of working life" concepts of the 1960s and 1970s and then develops into a debate on what constitutes a good job, which in turn spills over into methodological discussions of measurement and international comparison. It is in this latter area that international institutions, in particular the EU, have made a significant contribution. We conclude that the quality of employment has attracted more systematic attention from both policymakers and researchers in recent years as internationally comparable data becomes available.

In this context, we ask what the ILO's concept of Decent Work has contributed to the subject, and what its impact has been. We conclude that only in Europe, where comparable indicators from harmonised surveys have now become the norm and constitute extremely valuable data for analysts, has significant progress been made. We consider that it is essential that this process of data collection and methodological consolidation be extended to other regions in the world where the quality of employment remains a neglected subject of study.

A note of caution to the reader is warranted: the account presented does not tell one coherent story and does not come close to the elaboration of a coherent framework for understanding and measuring the quality of work as the concept's inherent complexity makes the related literature and the policy debate conceptually confusing. Rather, the review shows how bodies of independent literatures evolved in parallel, with only very slow convergence towards a set of solid and consistent foundations for future research. We review significant methodological innovations that have led to new theoretical developments in work and employment, although we argue that this process is far from complete. Central to this debate 
is the development of employment conditions, their distribution and their precarious nature within the context of the global political economy.

\section{Theoretical approaches}

First steps towards the development of 'quality of working life' concepts and measures can be traced back to the late 1960s and 1970s. Their origins are linked to the research on the 'quality of life' indicators emerging at that time. The 'quality of life' approach challenged the attempts to quantify living conditions relying solely on economic dimensions (such as GDP or unemployment) and consequently was seen as a better approach to understanding the human meaning and consequences of major social and technological changes occurring during a period of prosperity (Land, 1975). For most developed Western societies 'more' ceased to equal 'better' so that material prosperity was challenged by a concern with improving 'quality of life'. This perspective, emerging in the mid-1960s in the United States, is often referred to as the 'Social Indicators Movement', and gained significant scientific influence (Noll, 2004). The publication of a book entitled Social Indicators in 1966 signified the launch of the movement and advocated the development of a system of social accounts suitable to guide policy decisions (Bauer, 1966). The nature of employment and quality of work were immediately included in the research agenda, focusing on non-pecuniary aspects of jobs and individuals' experiences of their working environments (Seashore, 1974; Biderman, 1975; Davis, 1977). However, from the outset it was clear that the 'quality of (working) life' research lacked appropriate data and methodologies for measurement (Bauer, 1966). Discussions of quality of employment aspects also cropped up in other bodies of literature as globalization and deindustrialization began to effect employment conditions in developed countries, particularly in the United States, where changes were more abrupt (Bluestone and Harrison, 1984; Loveman and Tilly, 1988; Rifkin, 1995).

One of the first ways in which the academic literature approached the question of what constitutes a "good job" was by focusing on workers' own evaluations of their jobs (Staines \& Quinn, 1979; Yoshida \& Torihara, 1977) as a way of measuring labour market outcomes. Seashore (1974), for instance, defined good jobs as those possessing attributes which are valued by the worker and lead to job satisfaction. Wnuk-Lipinski (1977) saw job satisfaction as an important part of the quality of life and thus as an end in itself. Based on this perspective, a number of criteria for assessing the quality of work were devised, encompassing both general measures of job satisfaction as well as specific measures of workers' contentment with an array of job facets (Kalleberg \& Vaisey, 2005; Krueger et al., 2002; Land, 1975; Staines \& Quinn, 1979).

This highly subjective approach was not without its critics. Depending on workers' preferences, job characteristics may be valued quite differently (Taylor, 1977). Thus, in the literature, attitudinal measures are complemented by a concern for 'objective' aspects of jobs. Despite no consensus ever having been reached as to what constitutes a good job, a range of theories indicate what 'objective' features should be taken into account (Warr, 1987).

To give just a few examples of such theoretical perspectives, the Neo-Marxist tradition emphasised the individual's self-development and autonomy, focusing on the alleged simplification of work tasks, de-skilling and the growing separation between head and hand or the planning and execution of work (Braverman, 1974). Since the start of the 1970s occupational psychologists have also done much research on job quality, following the tradition of ergonomists. This approach focused on determinants of subjective well-being and productivity at the level of task characteristics, such as variety, challenge, meaningful work, autonomy and team work (Hackman \& Oldham, 1975). The policy focus of this work was single-firm-specific and aimed to bring about improvements in individual workplaces. Specialist 
surveys of job quality were undertaken, and psychometric techniques were used to predict worker wellbeing, motivation or productivity. With the increasing capabilities of the workforce, a job-worker match (Rozen, 1982) and perceived skill utilization (O'Brien \& Feather, 1990) were also suggested as components of job quality.

In the 1980s, new health hazards and the replacement of physical effort by psychological stress directed attention to health outcomes and control over the work process (Karasek \& Theorell, 1990; Dhondt, Kraan, \& Sloten, 2002). These developments were taken up again by sociologists in their debates on varieties of capitalism and production regimes. They focussed on aspects of work experience critical for the quality of employment that are affected by the nature of production regimes, thus putting emphasis on skill levels, the degree of job control, participation at work and job security (Hall \& Soskice, 2001; Gallie, 2007). The increasing centrality of work-life balance issues in the 1990s also focused attention on the scheduling and duration of working time. ${ }^{2}$

International institutions have also made important theoretical efforts to conceptualise the quality of employment. Arguably the most pronounced example of institutional initiatives is the concept of "Decent Work" launched by the ILO and declared its institutional priority in 1999. It followed from the increased importance that aspects of the quality of employment were acquiring during the 1980s and 1990s as a result of the visible impact of globalisation and market liberalisation on employment conditions. In the words of the ILO's former Director-General, Juan Somavía: "the primary goal of the ILO today is to promote opportunities for women and men to obtain decent work and productive work in conditions of freedom, equity, security and dignity" (ILO, 1999). Decent Work thus juxtaposes the generation of employment itself with the conditions under which it is generated as well as workers' rights and their voice in the community. This definition was formulated in a deliberately broad manner that took into account the priorities of the ILO's tripartite constituency: governments, employers and unions. The immediate question that arose from this all-encompassing definition based on the rights and entitlements of workers was how such a broad approach could be operationalised. As we will see below, this question remains largely unresolved.

Almost in parallel to the ILO's launch of Decent Work, the EU began to focus more explicitly on the quality of jobs. The promotion of good working conditions and the provision of social security have long been core elements of the European social model. However, the quality of work was only institutionalised as the EU's employment policy objective in 2000 in the Lisbon Treaty. The goals set by the Lisbon development agenda included 'sustainable economic growth with more and better jobs', and a set of indicators was agreed upon at the 2001 meeting of the European Council in Laeken (EUROPA, 2001).

This overview of the quality of employment literature reveals the extent to which multiple and relatively diffuse concepts have developed in parallel. First, we must highlight the extent to which the terminology used is confusing: expressions such as 'quality of working life' (predominantly linked to workers' own evaluations of one's job), 'job quality' or 'quality of work' (often focusing on the job content and work environment), and finally 'quality of employment' and 'decent work' (which include all of the above as well as other issues such as labour relations, rights, gender gaps, and work life balance) are often used interchangeably without clear definitions. This reflects the complexity of the issue of quality of work: there are not only multiple facets of jobs that should be taken into account, but also multiple levels on

\footnotetext{
${ }^{2}$ It is relevant to note that dimensions related to the quality of employment have also cropped up in other bodies of literature related to what we examine here. For example, the literature on international trade has included discussions of standard and non-standard employment, as well as of labour standards. However, analysing this in detail would go beyond the scope of this paper.
} 
which jobs can be analysed, ranging from a particular work environment to broad labour market systems in which jobs are performed. It also reflects the fact that different academic disciplines have focused on different aspects of the quality of employment.

Second, we must distinguish between the academic and institutional literature that has developed. While the process of academic research has been organic and diffuse, international institutions such as the ILO and the EU have attempted to develop and operationalise these theoretical concepts for their own purposes within the constraints imposed by their tripartite constituents.

Finally, and as we will see below, the theoretical literature that conceptualised the quality of employment is often intertwined with methodological discussions of its measurement. In fact, all theoretical approaches sooner or later have to confront the question of how the quality of employment can be measured. Without appropriate methodologies for measurement, the concept of the quality of employment itself leads nowhere.

\section{Methodologies for Measurement and International Comparisons}

The literature on the measurement of the quality of employment has had to confront difficulties on multiple levels. First, successful measurements require reliable, and preferably also comparable, sources of data. As we will see in this section, theoretical and methodological advances on the subject of the quality of employment are closely related to data availability. Conversely, data availability and comparability further theoretical and conceptual progress. The availability of comparable data across European countries has thus generated a virtuous circle in which empirical evidence has expanded the theoretical understanding of labour markets, which in turn has increased the efforts invested in data gathering.

A second problem that the measurement of the quality of employment has to confront is the question of which level of the labour market we are looking at. Whether we are interested in individual workers, jobs themselves, the regulatory environment, or the labour market as a whole generates different data requirements and methodologies of measurement.

Third, we must highlight the main problem with measuring the quality of employment: there is no simple set of variables that can undisputedly be thought of as summarising what constitutes a good job. This point marks an important contrast with the highly successful launch of the human development indicators in 1990. While it is difficult to dispute that it is better to live a longer, healthier, more educated life with a higher level of disposable income, many labour market variables are disputable. This is a problem that the ILO as a tripartite institution in particular has had to confront: while higher wages may be better for workers, employers would argue that they prevent employment generation. While greater job stability may be preferred by some workers, others may prefer moving between jobs. The interests of workers, employers, and public policy makers often clash, as do the interests of individual human beings and "free markets". This conceptual confusion and political vested interests are real, but not insurmountable. The experience of the $\mathrm{HDI}$ is that once attempts are made to measure these concepts, albeit imperfectly, then progress can be made in tackling the conceptual issues and deflecting political partisanship.

The discussion that follows in this section demonstrates how each of these measurement difficulties has played out in the literature. However, we also show how successful analyses deal with these problems. We begin with examining how the literature has dealt with the problem of available data: this has led to a host of studies on one or two aspects of the quality of employment, while the number of studies that have attempted to develop a comprehensive framework taking account of multiple job characteristics is limited. 


\subsection{Methodology and Measurement in the Academic Literature}

The academic research that measures selected employment conditions that are conducive to a better quality of working life is built upon a solid theoretical foundation and a large body of empirical work (Adams et al, 2000; Dex and Bond, 2005; Gallie et al, 2004; Green, 2006; Kalleberg, 2011; Olsen and Kalleberg, 2004; Rose, 2003). This generated a considerable understanding of the various job characteristics conducive to workers' well-being within national labour markets. However, even despite this solid theoretical and empirical foundation, no consensus was ever reached as to what exactly constitutes a "good job" or how best to operationalise the idea in a synthetic or compound measure. Again, the abovementioned multiple and diverging focuses of different academic disciplines on the subject do not help in this regard. It is hardly surprising then, that the translation of these complex and heterogeneous concepts into a policy relevant, cross-country comparative analysis have taken so long to emerge. Moreover, the vast majority of existing indicators was developed based on single country datasets. Consequently they tell us little about national comparisons. Where such studies have been done, they tend to be limited to the member states of the EU. Overall, these studies can be divided into roughly three groups: a first that uses self-reported data and/or evaluations such as job satisfaction to estimate job quality, a second group that used objective data, and a third one that uses a mixed approach.

The development of a measure of the overall quality of jobs based on evaluations of job satisfaction proved to be extremely problematic. Agassi (1982) argues convincingly that job satisfaction measures the relationship between the quality of an employee's current job and the employee's idea of what might reasonably be expected of a job. To this we must add the notion of adaptive preferences (as used by Amartya Sen (1999a) and Martha Nussbaum (2000)), which conceptualises the ability of people to adapt to unfavourable circumstances (including poor employment conditions), which distorts their ability to evaluate their job characteristics objectively (See also Comin and Teschl, 2005). As expectations vary considerably between countries, it is often the case that a developed country has lower aggregate job satisfaction than a developing country. The same process can explain why some less advantaged groups of workers (e.g. women) have higher satisfaction levels than workers with objectively better working conditions, if the more advantaged workers also have higher expectations of their jobs (see also Muñoz de Bustillo et al, 2011). Whilst this is an interesting psychological phenomenon, it renders job satisfaction measures unsuitable for comparative research on job quality.

The focus of many indices proposed in the literature is therefore on the intrinsic quality of jobs, i.e. their objective characteristics. Some scales are quite simple and onedimensional, for example limited to skill utilization (O'Brien \& Feather, 1990), while others incorporate a variety of features conductive to workers' motivation, including skill variety, task identity, task significance, autonomy and job feedback (e.g. Long, 1993). Some proposals aim to go even further in the direction of objectivity of measures obtained by avoiding perceptual data from employees altogether. Thus, Hunter (2000) proposes looking at good job practices provided by the employer that are arguably conductive to workers' well-being, such as employer contributions to health plans, education, compensation plans, provision of child care programs, or high wages and promotion opportunities. The endeavour to find the lowest common denominator for job quality free from any self-report bias led some authors to define good jobs in more narrow terms (Johnson \& Corcoran, 2003: hours worked, salary and health benefits; Sehnbruch, 2006 and 2007: income, contractual status, tenure and vocational training; or Floro \& Messier 2011: income, work hours, number of jobs, job security and nonwage benefits). Thus, despite the agreement that it is necessary to go beyond wages in the assessment of job quality, pay retained a prominent position as a reliable, although not comprehensive, variable that overcomes the dependence on individual characteristics, life 
situation, or background (Rosenthal, 1989). There have been other suggestions too of using administrative data as a proxy for particular features of job quality, for instance aggregate statistics on accidents or fatalities at work as a proxy for dangerous work.

A third approach was adopted by Jencks et al (1988) in their Index of Job Desirability, which combines the objective job features that were expected to contribute to job quality with workers' assessment of their relative contribution. The authors started with a collection of 48 job features, from which they selected those affecting to the greatest extent, on average, workers' positive evaluations of their jobs. The purpose was to establish what objective characteristics of jobs are commonly perceived as 'good', overcoming the jobholder's subjectivity and personal values. Thus, having a desired job according to this index might be a matter of getting what employees want on average, even if this is not what is wanted by a particular job incumbent. This approach, however, is also problematic (and has not achieved much impact), as it depends on the assumption that all workers are familiar with the reference job.

Variations of a mixed approach that integrate measures of 'objective' working conditions with measures of the impact they have on job satisfaction or overall job ratings can also be found in rare examples of cross-national studies (Kalleberg \& Vaisey, 2005; Tangian, 2009).

Among the most recent publications, two models represent particularly important and useful contributions. The first, by Körner et al, (2009), takes a broader perspective and encompasses other aspects of employment; the second, by Green and Mostafa (2012), is a model that explicitly focuses on job quality. These approaches are both conceptually more advanced than previous attempts to measure the quality of employment, their indicators both use the basic needs approach as a theoretical foundation, and also have the advantage of good international datasets to develop and refine their operationalisation, giving grounds for optimism that we are close to internationally agreed frameworks for the measurement of quality of employment.

Körner et al's (2009) model of the quality of employment consists of seven dimensions of the quality of employment, arranged in a pyramid resembling the Maslow's hierarchy of needs, with the most basic dimensions at the bottom and the more aspirational dimensions at the top, as shown in Figure 1. However, this model also incorporates country-level statistics, such as accidents at work and measures of social protection. Thus this model measures quality of employment at the national level, making it impossible to compare workers within a country such as male and female workers or rural and urban workers unless very detailed sectoral data exists. The scheme has been piloted with German data to illustrate its application. Because it uses data from a number of different sources, some international and some national, it is not straightforward to replicate the indices in other countries so it is primarily a tool for countrylevel case studies rather than international comparisons.

Figure 1. Körner et al's Quality of Employment 7-layer model 


\section{Seven dimensions of quality of employment}

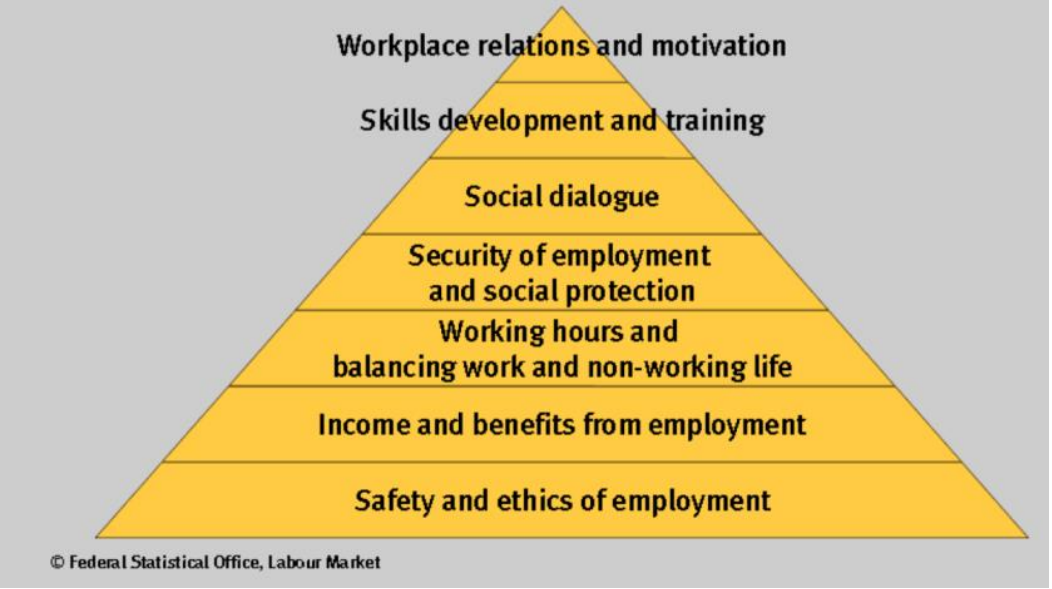

By contrast the model of the quality of employment developed by Green and Mostafa (2012) is derived from a singular dataset. In fact, there have been a number of reports, commissioned by the European Foundation (an EU body) to compare particular features of job quality, based on the European Working Conditions Survey (EWCS), between all EU member states (Burchell et al, 2009; Pacelli et al, 2008; Dhont, 2005), as well as general five yearly overviews of working conditions in the EU member states (Parent-Thirion et al, 2012). However, it has not been until now that a report has been commissioned explicitly to take a comparative overview on job quality between member states.

In their report, Green and Mostafa use the 2010 EWCS to develop their measure, influenced from literatures in psychology, sociology and economics. The model consists of four dimensions of job quality: earnings; job prospects; working time quality and intrinsic quality of the job. Each respondent in the EWCS is given a score on each of these dimensions. Thus it is possible to compare average job quality for any subgroup within the dataset, for instance by country, gender or age. To illustrate the practical usefulness of this methodology, Figure 2 shows the average intrinsic job quality by country (relative to Turkish workers who scored the lowest on this dimension). This figure shows many expected findings, such as the high score for Denmark and the low score for Turkey. However it also throws some surprises worthy of further investigation. For instance, the high job quality scores for Latvia and Poland were not predicted, nor was the fact that France would score so poorly. No doubt other researchers will want to check these findings, refine the model and improve it. The public availability of the single dataset that the indices are derived from allows researchers critical replications and improvements to the model.

\section{Figure 2. Intrinsic Job Quality, by country relative to Turkey}




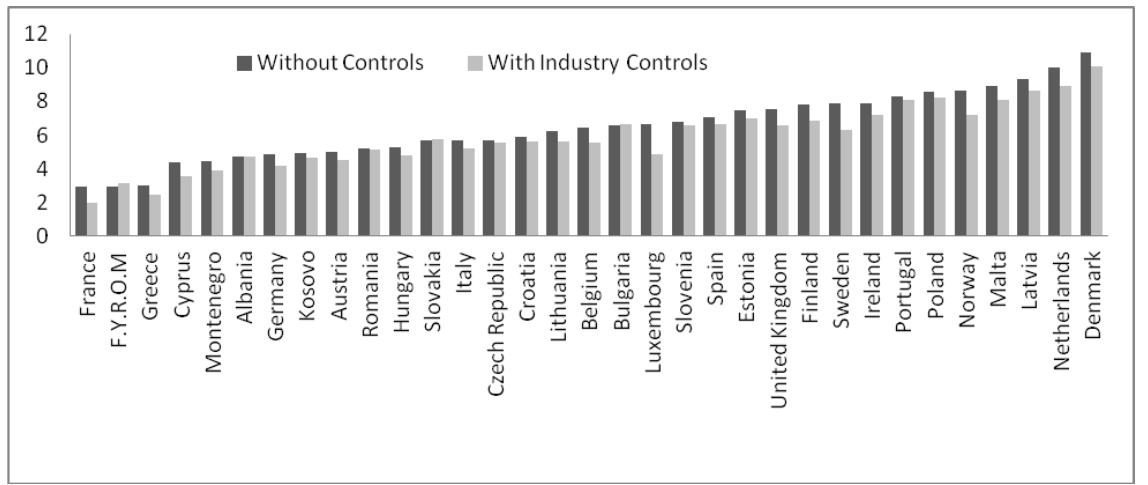

Source: Green and Mostafa, 2012.

Reinecke (2006) attempted an analysis of job quality in Latin America, to assess the effects of globalisation. He set out to cover a wide range of aspects of job quality, influenced by the Decent Work agenda, and conceptualising job quality on 12 dimensions with much overlap with the Laeken indicators and Mostafa and Green's model. However, the lack of international comparative data in Latin American countries meant he had to fall back on a much smaller and impoverished list of proxies to employment quality that were available in more than one country such as wages, social security coverage and unionization rates.

\subsection{Levels of Analysis}

As we can see from this discussion, one of the unresolved issues in the literature on quality of employment involves deciding what types of information should be included in measures of job quality. At the simplest and most individualistic level, some models are only involved in the attitudes of individuals (e.g. their job satisfaction) and ignore details of the job itself or the context of the job. At the other extreme, some models are concerned more with the macrolevel context of jobs such as the level of legal protection to workers provided by the state, welfare types that reduce the costs of job loss and the state of the labour market to account for the risk of job loss and unemployment.

Although schemes incorporating these multiple levels of analysis are clearly more comprehensive, they also have important drawbacks. First, by incorporating aggregate data which is often incompatible between countries, it makes international comparisons problematic, unlike Green and Mostafa's job quality indices where such comparisons are straightforward. Second, by retaining the job as the unit of analysis, researchers are free to analyse job quality data in a number of different ways: for instance, job quality measures can be incorporated either as dependent or independent variables in a regression model of employees, and the unit of analysis can be aggregated upwards to regions, ethnic groups, or the national level. However, disaggregating national-level quality of employment data is at best problematic. In any case, indicators of job quality are a necessary pre-requisite for a more comprehensive measure of the quality of employment. Therefore, if one is proceeding incrementally, the obvious starting point is the construction of measures of job quality; these can then be extended into a measure of quality of employment as other types of data are added. 


\subsection{Two Contrasting Institutional Approaches to the Dilemma of Measurement: the ILO's Decent Work}

As discussed above, one of the main problems with measuring the quality of employment is the fact that it is difficult to reach universal agreement on what constitutes a good job. This poses particular difficulties for international bodies where any progress is based on a compromise between the interests of employers, policymakers or employees. The literature reviewed in this section suggests that this is one of the main reasons why institutional initiatives to build a universally applicable methodology for the measurement of quality of work have so far been unsuccessful.

When the ILO launched its concept Decent Work in 1999, expectations among labour market analysts were raised hoping that the concept would lead to new measurements, more extensive and internationally comparable data gathering, synthetic employment indicators and theoretical advances in our understanding of the functioning of labour markets. A first attempt to synthesise employment indicators was made by the ILO's Regional Office in Latin America and the Caribbean, which proposed a very basic indicator (see ILO, 2001). The index, applied in Latin America between the years 1990-2000, contained information about the evolution of the employment situation of 15 countries during the decade. It was composed of seven indicators related to employment (unemployment, informality), income (industrial wage, minimum wage and the wage gap between men and women) and workers' social protection (social security coverage and hours worked). Four new strategic dimensions were incorporated into this index in 2002: compliance with labour standards, quality of work, social protection and social dialogue. Thus, according to this new index, countries would record an improvement if they increased the ratification of work conventions, the unemployment rate decreased, the quality of jobs progressed (measure by the reduction of informality), the purchasing power of industrial and minimum wages raised, the income gap between the genders fell, the coverage of social protection was increased, there was an increasing degree of unionization or the percentage of workers involved in labour disputes decreased (Lanari, 2005; ILO, 2001, 2002).

These efforts were expanded in 2003 when the International Labour Review, an academic journal published by the ILO, dedicated a special edition to the measurement of Decent Work. Its contributing authors presented different methodologies of how Decent Work could be operationalised. For example, Anker et al (2003) propose an extended range of indicators that would capture the concept. However, the authors recognise that the measurement of Decent Work is severely constrained by the availability of internationally comparable data on employment conditions. In the same volume, Bescond et al. (2003) propose a different methodology based on seven different Decent Work indicators, while Bonnet, Figueiredo and Standing (2003) present the establishment of a family of Decent Work indicators from different sources that take into account various aspects of security. Overall, this special issue highlights several difficulties with the concept of Decent Work. First and foremost, as the authors themselves note, internationally comparable data on Decent Work issues across both developed and developing countries is almost non-existent. In fact, the results of the Bescond et al. article highlight that without comparable data, methodologies for the measurement of Decent Work make little sense if they end up showing that the Decent Work deficit of the Russian Federation is lower than in the UK, the United States or Japan, or that Spain and Italy have worse working conditions than Tanzania or Nepal.

Second, the articles present different methodologies, all of which represent valid alternatives for measuring Decent Work concept. However, given the absence of comparable data, none of the methodologies presented stands out as technically superior. Instead, the articles highlight the many different methodologies for the measurement of Decent Work that can be used, and that the results produced by these methodologies may vary greatly. Finally, it is noteworthy that this is the only collection of articles published by the ILO that present such 
summary methodologies. This 2003 volume generated much internal debate within the ILO, and much resistance from both governments and employers to the practice of ranking labour markets. For a long time, this was therefore the only publication that produced any kind of compound indicator of Decent Work, although the debate within the ILO with regard to the need for a compound indicator persisted (see for example Ghai, 2006 and Godfrey, 2006).

However, after these initial efforts, progress on the measurement and definition of Decent Work stalled as employers (and to a certain extent also governments) objected to being classified or ranked according to yet another index, which would again highlight the weaknesses of certain countries. In 2008, the International Organization of Employers stated that Decent Work does not set clear parameters and does not take into account the particular conditions of each labour market (Lanari 2005, IOE 2002). In addition, many labour market analysts objected to the idea that Decent Work could be summarised in a compound indicator. While some experts were clearly convinced of the need for a comparative indicator which would operationalise Decent Work, others defended the idea that the concept was too complex for such a simplistic approach, and that any standardised methodology would gloss over the details of very heterogeneous labour market situations that the disaggregate approach highlights (ILO, 2008). For example, many gender experts objected to the idea of summarising Decent Work in a country-level composite indicator as this would de-emphasise the very disparate employment conditions of men and women.

In response to these conceptual difficulties, the ILO carried out a tripartite meeting of experts in 2008 at which the institution's progress on implementing the Decent Work approach was reviewed. The meeting proposed a new set of 19 core indicators, 25 additional indicators and another 8 variables related to the socioeconomic context of member countries. ${ }^{3}$ The meeting agreed on the need for establishing a consistent methodology for the measurement of Decent Work based both on indicators of quantity and quality while simultaneously emphasising the need for improved data. The following year, in 2009, the ILO's new Statistics Department was launched with the brief to improve data collection and establish user-friendly country profiles, which would compile information for each country. ${ }^{4}$

As this discussion illustrates, the ILO has still not produced a universally applicable methodology for the measurement of Decent Work. Lanari (2005) argues that the concept's main contribution has been its integrative vision as well is its claim to universal ethics. However, many critics view Decent Work as a term that has yet to be filled with content, or that simply recycles previously existing ideas under a new name. The absence of internationally comparable data compounds this difficulty.

\subsection{Two Contrasting Institutional Approaches to the Dilemma of Measurement: the European Union}

A somewhat different approach to the ILO's Decent Work was adopted by the EU, which focuses on job quality. As discussed in section 2, the strategic goal of "more and better jobs" was set in the Lisbon Treaty in 2000. To monitor the progress towards the reviewed principles of employment policy agenda, the European Council, meeting in Laeken in 2001, agreed on a portfolio of 18 statistical indicators. Despite the fact that the Commission's initial proposal was quite comprehensive and defined quality of work based on ten dimensions, it was also subject to a process of tripartite political negotiation, which resulted in a much

${ }^{3}$ Details on this methodology can be found on: http://www.ilo.org/integration/themes/mdw/lang-en/index.htm. See also ILO, 2012.

${ }^{4}$ So far the ILO has produced approximately 17 country profiles with several more underway. However, due to data differences, the country profiles are not comparable in terms of their statistical indicators. Instead, the ILO works with whatever information each country has available. 
narrower set of measures. Thus, the Laeken proposal ultimately did not go much beyond basic 'key' indicators taken from national labour force surveys, such as unemployment, education and health. It left out many important dimensions (e.g. wages) and merged quite diverse phenomena, such as quantity of employment or mobility, and was therefore also the subject of much criticism (Dieckhoff \& Gallie, 2007; Davoine et al., 2008; Peña-Casas, 2009; Bothfeld \& Leschke, 2012). Various subsequent initiatives to improve the Laeken proposal tried to incorporate alternative indicators of job quality. For instance, with the renewed social agenda, a number of principles for good work was presented along with some more detailed measurement of the conditions of work (European Commission, 2008). However, many of the initial weaknesses remained, resulting in a disorganized aggregation of variables describing jobs, policies, participation rates and various forms of distributional inequalities.

In parallel to the Laeken indicators, a dialogue has developed between major stakeholders (UNECE, ILO, Eurofound, trade unions, etc.) to elaborate a broader, multidimensional conceptual framework for the measurement of the quality of employment. It is due to this effort that a wider scope of employment data from the European Working Conditions Survey, the European Social Survey or the EU Statistics on Income and Living Conditions has been incorporated into the production of employment statistics, and various new indices of job quality have been proposed and refined in an ongoing debate (See our literature review in Section 2, for example Leschke, Watt and Finn, 2008). Yet this dialogue also faced many obstacles similar to those of the Decent Work agenda and after twelve years of having established the initial task force, the debate about the conceptualisation of the quality of employment is still ongoing.

Nevertheless, the improved data generation produced by these efforts has led to more in-depth and methodologically sophisticated studies of the quality employment, such as those discussed in the previous section. In addition, recent models to encapsulate job quality into a smaller number of compound measures may be a considerable improvement on earlier attempts to draw together all job quality indicators into a tractable framework.

These approaches to definitions and data gathering throw up the question of their relative success. What has been the impact of the ILO's Decent Work approach compared to other processes of data gathering?

\section{Impact and Conclusions for policy makers}

One way of answering this question is to examine the impact that each approach has had on the relevant literature through cybermetric searches. A simple Google Scholar search already gives us an indication, even though it is an imperfect research tool. Unfortunately, searches in Google as well as in academic catalogues such as JSTOR cannot be filtered to the extent that would be desirable for research of this kind. For example, we cannot filter searches by regions or country, or by academic subject. The results below therefore include references that are not strictly relevant to our subject area, such as articles from the management sciences on job satisfaction. $^{5}$

Despite these limitations, researchers are using these types of cybermetric searches as basic measures of impact (Ramos, 2006). From the graph below we can see that the concept of job satisfaction is mentioned more frequently in the scholarly literature than the quality of employment and other terms. The most notable conclusion of Figures $3-4$ is that the ILO's concept of Decent Work hardly gets a mention at all in the academic literature, a fact that will

\footnotetext{
${ }^{5}$ The only way of filtering Google search results would be through a manual analysis, which, of course, would require an infinite amount of resources.
} 
be discussed in more detail below. On the few occasions that 'Decent Work' is discussed, this occurs in the ILO's own in-house journal, the International Labour Review.

Figure 3. Number of entries for each of the keywords in Google Scholar, per year for the two periods

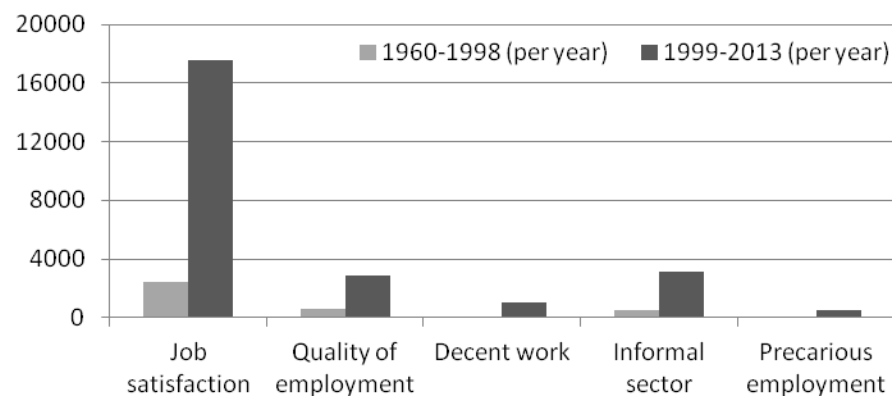

Note: Each term entered in parenthesis to search for exact phrase.

'Quality of employment' includes: Quality of work, Job quality and Quality of employment.

These results are replicated by searches on different levels. If we narrow the search universe to the academic journal articles listed by JSTOR we obtain similar results (Figure 4). While it is clear from Figure 4 that the terms relevant to the quality of employment have all been used in the academic publications over the past years, we can also see that 'Decent Work', has been used less than any of the other terms.

Figure 4. Number of entries for each of the keywords in JSTOR, per year for the two periods

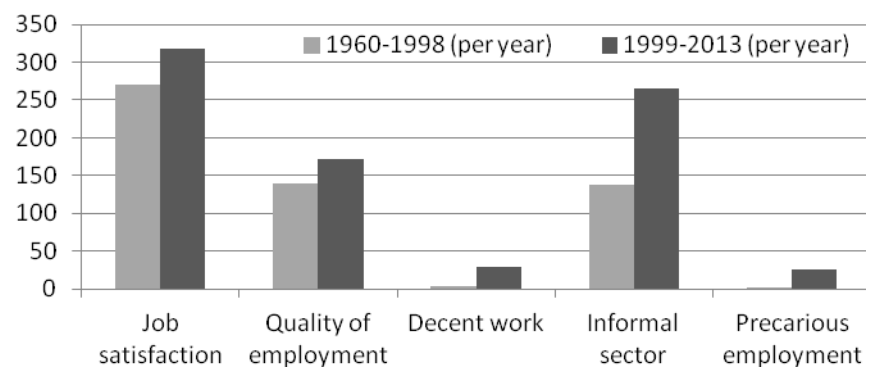

Note: Each term entered in parenthesis to search for exact phrase.

'Quality of employment' includes: Quality of work, Job quality and Quality of employment.

In these searches we have included the informal sector, a concept which was launched by the ILO in 1972, and which had significantly more impact in the academic literature than decent work, as we can see from the above graphs. In fact, the informal sector has penetrated the literature to such an extent that is still the predominant concept used today by many labour market analysts, many of whom are not even aware that decent work indicators should 
have replaced it. ${ }^{6}$ It is important to bear this point in mind as it shows that the ILO as an institution is perfectly capable of launching a successful development concept.

We must therefore conclude that the extent to which Decent Work has penetrated the academic literature has been extremely limited. Although impact on academic literature is also not a perfect measure of overall impact, it does give us a good indication of the penetration achieved by a development concept such as decent work. ${ }^{7}$ After all, one of the objectives at an international development concept should achieve is further research and discussion by independent experts, many of whom are academics.

Perhaps the most important point to bear in mind is Ward's analysis of the relative success of United Nations indicators: he concludes that only those indicators that are simple and easy to understand, that summarise only a few variables, and that are internationally comparable are ultimately successful (Ward, 2004).

So far in this paper we have shown that concepts related to the quality of employment attract much research in the European context and are starting to be actively used by EU policymakers in determining the future directions of labour markets. However this is hardly the case in other countries. How can we explain this difference? We would like to offer an explanation based on three overlapping ideas.

First, we argue that internationally comparative data on working conditions is central to progress. 25 years ago there was very little internationally comparable micro-level data in Europe, making comparisons of labour markets or other aspects of quality of life costly and time-consuming. There were occasional attempts by researchers to collect comparable data from more than one country, but even then it was beyond the budgets and time horizons of individual research teams or agencies to collect data at more than one point in time.

This situation has changed dramatically in Europe. Starting with the standardisation of various labour force surveys in EU member states, there followed a number of initiatives that have provided rich and dynamic data sources for researchers to explore ideas and test theories about labour markets. These datasets not only facilitate statistical comparisons of countries' labour markets; they also provide a fertile environment for rapid theoretical developments in the understanding of how labour markets operate, and the drivers of job quality. Researchers can demonstrate the usefulness of their conceptual approaches by applying their theoretical frameworks to internationally comparable data, and other researchers can respond constructively with further analyses from the same or other datasets.

Europe's progress in this regard illustrates an important point: why has the EU been able to generate internationally comparable survey data while the ILO has not? Also, why has Europe as a region produced such data while the United States on the other hand has been lagging since the 1970s? The main explanations for these differences are political, more specifically they are related to political will. ${ }^{8}$ In the case of the ILO, there has been no political will to undertake international employment surveys, and little progress has been made in persuading member governments to implement standardised labour force surveys that would permit the calculation of a broad range of internationally comparable indicators on employment conditions. Again, the ILO's tripartite structure is probably an important factor

${ }^{6}$ For an overview of the literature on the informal sector, see Gerxhani, 2004. Also, the World Bank's 2013 World development report and still uses the informal sector concept much more frequently than any references to decent work.

${ }^{7}$ Alternatives to academic searches would be searches of articles published in the international press or of government publications. Of these methods, the former runs into the same problem of limited filtering possibilities, while the latter is impossible as there is no centralised source of government publications. ${ }^{8}$ This argument is based on numerous interviews undertaken with labour market experts from all over the world for this paper. 
that hinders such efforts. ${ }^{9}$ In the case of the United States, is similar explanation of lack of political will can be put forward. ${ }^{10}$

Second, the nature of the research communities examining quality of employment concepts is crucially important. The academic research community consists primarily of nonpartisan researchers. Whilst interested in the policy implications of their research they are not constrained to tell a particular story that might be viewed differently by the various social partners, namely employers, trade unions and governments. This contrasts sharply with the ILO, which being a tripartite organisation in which employers' organisations, trade unions and governments are actively involved, is a highly politicised environment where each of these parties has a particular concern for the directions and conclusions of that research.

Third, the academic process of defining the quality of employment has been organic; for instance many of the lessons of the social indicators movement in the United States were later taken up by comparative researchers in Europe. This evolution of ideas, although nonlinear, has led to clear advances over the decades. Gradually, fuzzy and poorly defined concepts have solidified into forms that can inform policy. This contrasts sharply with the history of Decent Work. The latter was defined from the start; not as a working hypothesis but rather as a mission statement that came to define the role and values of the ILO. It was therefore expressed in terms of universal values such as freedom, fairness and dignity. Thus it was never clear which parts of the Decent Work were fundamental assertions of the ILO's values, and which parts were legitimate topics for research and development.

Unfortunately the initial definition and articulations of Decent Work, whilst aspirational, were also conceptually confused. For instance social dialogue might more appropriately be seen as a driver of Decent Work rather than part of the definition of Decent Work. Some aspects of Decent Work are aimed at the individual worker (e.g. child and forced labour), some at the level of the working environments (e.g. health and safety) and some at the aggregate level (e.g. social protection legislation). This has the further consequence that Decent Work cannot be operationalised at the level of the individual worker or the job, so perfectly reasonable and interesting questions such as gender gaps in job quality or the quality of employment for migrants cannot be addressed straightforwardly.

However while the nature of the academic research community and its research process are undoubtedly important, the search results shown above of the ILO's own concept "informal sector" demonstrate that the institution can be potentially very successful in promoting a concept related to employment. But unlike decent work, the ILO's definition of what constitutes the informal sector was accompanied by a simple and clear definition that is easy to understand, as well as by a process of data gathering and harmonisation that allowed for internationally comparable research. The latter in particular required persuading national statistical institutes to adopt internationally standardised labour force survey questionnaires and definitions. ${ }^{11}$ The efforts that backed the adoption of the informal sector illustrate that the level of political will at the institutional level is crucial to a concepts success or failure.

\footnotetext{
9 This explanation was given to us by numerous senior ILO officials during interviews undertaken in Geneva as well is in regional offices during 2012 and 2013. In this context, it should be noted that the ILO did manage to persuade individual governments to produce homogeneous data during the 1950s and $60 \mathrm{~s}$, which allowed for the production of basic comparable variables such as employment, unemployment and participation rates, as well as for the calculation of informal sectors across a broad range of countries However, little progress has been made on data gathering since these initial efforts, with much opposition coming from national and international associations of employers.

${ }^{10}$ Interviews with US labour market experts undertaken between 2008-2012.

${ }^{11}$ While this process has not been perfect due to the difficulties of harmonising internationally comparable data and due to the need for redefining the original concept, the informal sector must nevertheless be considered a success story.
} 
Fortunately, it is obvious to see how we might extract ourselves from the current impasse in which decent work finds itself. Since the comparability of international employment data is still so limited, it would make sense to apply independent international employment surveys across regions to achieve harmonised datasets. If this data were then made available to the research community, this would provide researchers with the ability to compare job quality between countries, which would be the first stepping stones towards more comprehensive measures of the quality of employment. Only once this process is started might we see the sorts of attention to the improvement of people's working lives that could parallel the attention that the HDIs directed towards human development.

We have argued that, whilst a large number of theoretical positions and debates are both possible and desirable on the topic of quality of employment, the one thing that is most needed to facilitate both constructive debates and evidence-based policies is the availability of internationally standardised data on job quality. This goal is achievable and affordable, and should lead to high quality research on employment with a more international perspective in the next decade.

\section{References}

Adams, A, Lugsden, E, Chase, J, Arber, S and Bond, S (2000). Skill-Mix Changes and Work Intensification in Nursing. Work Employment Society, 14(3), 541-555.

Agassi, JB (1982) Comparing the Work Attitudes of Men and Women. Aldershot: Gower. Alli, B. 2009. Fundamental principles of health and safety at work. 2da.ed. Madrid: Ministry of Labour and Social Affairs, ILO, 2009. 304 p. Anker, R, Chernyshev, I, Egger, P and Mehran, F (2003). Measuring Decent Work with Statistical Indicators. International Labour Review, 142(2), 147.

Bauer, RA (Eds.). (1966). Social Indicators. Cambridge, Mass.: MIT Press.

Bescond, D, Chataignier A and Mehran, F (2003). Seven Indicators to Measure Decent Work. International Labour Review, vol 142 no2: 179 - 211.

Biderman, A (1975). Introduction. The American Behavioral Scientist (pre-1986), 18(3), 301

Bluestone, B. and B. Harrison (1984) The Deindustrialization of America: Plant Closings, Community Abandonment and the Dismanteling of Basic Industry, New York: Basic Books.

Bonnet, F, Figueiredo, J B and Standing, G (2003). A Family of Decent Work Indexes. International Labour Review, 142(2), 213-238.

Bothfeld, S., \& Leschke, J. (2012). "More and better jobs": is quality of work still an issue - and was it ever? Transfer: European Review of Labour and Research, 18(3), 337-353.

Braverman, H (1974). Labor and M monopoly capital. New York: Monthly Review Press.

Burchell et al (2009) Working conditions in the European Union: Working time and work intensity. Dublin: EuroFound.

Comim, F. and M. Teschl (2005)"Adaptive Preferences and Capabilities: Some Preliminary

Conceptual Explorations", Journal of Social Economy, Vol 63, 2: 229-247.

Davis, LE (1977). Enhancing the quality of working life. International Labour Review, 116(1), 53.

Davoine et al, (2008). A Taxonomy of European Labour Markets Using Quality Indicators. Universite Paris1 Pantheon-Sorbonne.

Dex, S and Bond, S (2005). Measuring work-life balance and its covariates. Work, Employment \& Society, 19(3), 627-637.

Dhondt, S, Kraan, K and Sloten, G (2002). Work organisation, technology and working conditions. Luxembourg: Eurofound. 
Dhondt, S. (2005). Time constraints and autonomy at work in the European Union (Summary). Dublin: EuroFound.

Dieckhoff, M., \& Gallie, D. (2007). The renewed Lisbon Strategy and social exclusion policy. Industrial Relations Journal, 38(6), 480-502.

EUROPA - Press Releases. (2001). Employment and Social Affairs Council, http://europa.eu/rapid/pressReleasesAction.do?reference=MEMO/01/408\&format=H $\mathrm{TML} \&$ aged=0\&language $=E N \&$ guilanguage $=e n$

European Commission (2008). Employment in Europe 2008. Luxembourg: Office for Official Publications of the European Communities.

Floro, MS, and Messier, J (2011). Is there a link between quality of employment and indebtedness? the case of urban low-income households in Ecuador, Cambridge Journal of Economics, 35(3), 499-526.

Gallie, D (2007). Production Regimes and the Quality of Employment in Europe. Annual Review of Sociology, 33(1), 85-104.

Gallie, D, Felstead, A, and Green, F (2004). Changing Patterns of Task Discretion in Britain. Work Employment Society, 18(2), 243-266.

Gerxhani, K. "The informal sector in developed and less developed countries: A literature survey" Public Choice 120: 267-300, 2004.

Ghai, D (Ed.). (2006). Decent work; Objectives and Strategies. International Institute for Labour Studies. Geneva, Switzerland: ILO.

Godfrey, M. (2006). Employment Dimensions of Decent Work: Trade-offs and Complementarities, in Ghai, 2006 (Ed.), Decent Work; Objectives and Strategies, International Institute for Labour Studies, Geneva, Switzerland: ILO.

Green, F (2006). Demanding work. Princeton: Princeton University Press.

Green, F and Mostafa, T (2012). Quality of Work and Employment. Dublin: Eurofound

Hackman, JR and Oldham, GR (1975). Development of the Job Diagnostic Survey. Journal of Applied Psychology, 60(2), 159-170.

Hall, PA and Soskice, D (Eds.). (2001). Varieties of Capitalism. Oxford: Oxford University Press.

Hunter, L W (2000). What Determines Job Quality in Nursing Homes?. Industrial and Labor Relations Review, 53(3), 463-481.

International Association of Employers IOE , (2002).Trabajo Decente. Cómo llevarlo a la Práctica: el punto de vista de los empleadores. www.ioe-emp.org

ILO (1999), Report of the Director General: Decent Work. International Labour Conference, $87^{\text {th }}$ Session , Geneva.ILO, (2001). Índice de desarrollo del Trabajo Decente 1990-2000.

ILO, (2002). Nuevos Indicadores para el Índice de desarrollo del Trabajo Decente. Panorama Laboral 2002: 63-69.

ILO, (2008) The measurement of Decent Work. Report of the Director General. Geneva, November 2009.

ILO (2012) The ILO and the EU, partners for decent work and social justice; Impact of ten years of cooperation. Brussels, November, 2012.

Jencks, C, Perman, L and Rainwater, L (1988). What Is a Good Job? American Journal of Sociology, 93(6), 1322-1357.

Johnson, RC and Corcoran, ME (2003). The Road to Economic Self-Sufficiency. Journal of Policy Analysis and Management, 22(4), 615-639.

Kalleberg, AL, and Vaisey, S (2005). Pathways to a Good Job. British Journal of Industrial Relations, 43(3), 431-454.

Kalleberg, AL (2011) The Rise of Polarized and Precarious Employment Systems in the United States, 1970s to 2000s, New York: Russel Sage Foundation

Karasek, R and Theorell, T (1990). Healthy work. New York: Basic Books.

Körner, T, Puch, K and Wingerter, Ch (2009). Quality of Employment. Wiesbaden: Federal Statistical Office of Germany. 
Krueger, P, Brazil, K, Lohfeld, L, Edward, HG, Lewis, D, and Tjam, E (2002). Organization specific predictors of job satisfaction BMC Health Services Research, 2(1), 6.

Lanari, ME (2005). Trabajo decente. Buenos Aires, Argentina, Ministerio del Trabajo: 27.

Land, K (1975). The Role of Quality of Employment Indicators in General Social Reporting Systems. American Behavioral Scientist, 18(3), 304-332.

Long, R (1993). The impact of new office information technology on job quality of female and male employees. Human relations, 46(8), 939-961.

Loveman, G. and C. Tilly (1988) "Good Jobs or Bad Jobs: Evaluating the American Job Creation Experience", International Labour Review, Vol 127, No. 5

Muñoz de Bustillo, R, Fernández-Macías, E, Antón, Jl, and Esteve, F (2011). Measuring More Than Money. Cheltenham: Edward Elgar.

Noll, HH (2004). Social Indicators and Quality of Life Research. In N. Genov (Ed.), Advances in Sociological Knowledge (pp. 151-182). Wiesbaden: VS Verlag für Sozialwissenschaften.

Nussbaum, M. (2000) Women and Human Development: the capabilities approach, Cambridge: Cambridge University Press.

O'Brien, GE and Feather, NT (1990). The relative effects of unemployment and quality of employment on the affect, work values and personal control of adolescents. Journal of Occupational Psychology, 63(2), 151-165.

Olsen, KM and Kalleberg, AL (2004). Non-Standard Work in Two Different Employment Regimes. Work, Employment \& Society, 18(2), $321-348$.

Pacelli, L., Devicienti, F., Maida, A., Morini, M., Poggi, A., \& Vesan, P. (2008). Employment security and employability: A contribution to the flexicurity debate. Dublin: Eurofound.

Parent-Thirion, A., Vermeylen, G., van Houten, G., Lyly-Yrjänäinen, M., Biletta, I., \& Cabrita, J. (2012). Fifth European Working Conditions Survey - Overview report. Dublin: Eurofound.

Peña-Casas, R. (2009). Monitoring quality of work and employment in the European Union. Conceptual frameworks and indicators. In A. A. M. Guillen \& S.-Å. Dahl (Eds.), Quality of Work in the European Union: Concept, Data and Debates from a Transnational Perspective (pp. 41-86). Brussels: Peter Lang.

Ramos, C. and Acosta, E. (2006), "El Impacto de los Informes de Desarrollo Humano del PNUD en Chile". Universidad Alberto Hurtado, Depto. De Sociología.

Reinecke, G., WHITE, S. 2004. Policies for small enterprises: Creating the right environment for good jobs. Madrid: ILO / Ministry of Labour and Social Affairs, 2004. 253 p. (ILO reports, 69)

Reinecke, G. (2006) "Is Globalization Good for Workers? Definitions and Evidence from Latin America", International Labor and Working-Class History, No. 70: pp. 11-34

Rifkin, J. (1995) The End of Work: The Decline of the Global Labor Force and the Dawn of the Post-Market Era, Putnam Publishing

Rose, M (2003). Good Deal, Bad Deal? Work Employment Society, 17(3), 503-530.

Rosenthal, NH (1989). More than Wages at Issue in Job Quality Debate. Monthly Labor Review, 112, 4-8.

Rozen, ME (1982). Job Quality, Labor Market Disequilibrium, and Some Macroeconomic Implications. Journal of Economic Issues (Association for Evolutionary Economics), 16(3), 731.

Seashore, SE (1974). Job Satisfaction as an Indicator of the Quality of Employment. Social Indicators Research, 1(2), 135-168.

Sehnbruch, K (2006). The Chilean Labour Market: A Key to Understanding Latin American Labour Markets, Basingstoke and New York: Palgrave Macmillan.

Sehnbruch, K (2007) "From the Quantity to the Quality of Employment." In S. Alkire, F. Comim and M. Qizilbash (eds.) The Capability Approach in Human Development: Concepts, Applications and Measurement. Cambridge: Cambridge University Press.

Sen, A. (1999a) Development as Freedom, Oxford: Oxford University Press. 
Staines, GL and Quinn, RP (1979). American workers evaluate the quality of their jobs. Monthly Labor Review, 102(1), 3.

Tangian, A (2009). Decent work. European Review of Labour and Research, 15(3-4), 527-556.

Taylor, JC (1977). Job satisfaction and quality of working life. Journal of Occupational Psychology, 50(4), 243-252.

Ward, M (2004). Quantifying the World. Indiana University Press.

Warr, P (1987) Work, Unemployment and Mental Health: Oxford: Clarendon Press.

World Bank (2013) World Development Report: Jobs, Washington: World Bank

Wnuk-Lipinski, E (1977). Job Satisfaction and the Quality of Working Life. International Labour Review, 115(1), 53-64.

Yoshida, K and Torihara, M (1977). Redesigning Jobs for a Better Quality of Working Life. International Labour Review, 116, 139-152. 